Cytogenet Genome Res 111:96A (2005)

DOI: $10.1159 / 000085676$

\section{Assignment of the bovine tumor protein D52 gene (TPD523X) to the distal half of BTA14 with somatic and radiation cell hybrid panel mapping}

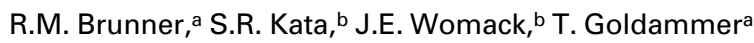
${ }^{a}$ Research Unit Molecular Biology, Research Institute for the Biology of Farm Animals Dummerstorf, Dummerstorf (Germany); b Department of Veterinary Pathobiology, Texas A\&M University, College Station, TX (USA)

Cytogenet Genome Res 111:96B (2005)

DOI: $\underline{10.1159 / 000085677}$

\section{Assignment of suppressor of cytokine signalling-2 (SOCS2) to porcine chromosome 5 with radiation hybrids \\ E. Piper, Y. Chen, C. Moran \\ Centre for Advanced Technologies in Animal Genetics and \\ Reproduction, University of Sydney, Sydney (Australia)}

Cytogenet Genome Res 111:96C (2005)

DOI: $\underline{10.1159 / 000085678}$

\section{Assignment of the calcium channel, voltage-dependent, $P / Q$ type, alpha $1 \mathrm{~A}$ subunit gene (CACNA 1A), and the ataxin 7 gene (ATXN7) to canine chromosome 20 by fluorescence in situ hybridization and confirmation by radiation hybrid mapping \\ H. Kuiper, ${ }^{a}$ C. Drögemüller, ${ }^{a}$ G. Evanno, ${ }^{b}$ R. Guyon, ${ }^{b}$ C. André, O. Distla \\ a Institute for Animal Breeding and Genetics, University of Veterinary Medicine Hannover, Hannover (Germany); b UMR 6061 CNRS, \\ Génétique et Développement, Faculté de Médecine, Rennes (France)}

Cytogenet Genome Res 111:96D (2005)

DOI: $10.1159 / 000085679$

\section{Assignment of murine placental} cathepsin $\mathbf{R}$ to mouse chromosome bands 13B2-B3 by fluorescence in situ hybridization

D.B. Zimonjic, a J. Liu, b W.-H. Xu, b. Zhou, a N.C. Popescu, a G.-P. Shib,c

a Laboratory of Experimental Carcinogenesis, National Cancer Institute,

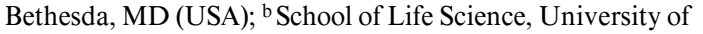
Technology and Science of China, Hefei, Anhui (P.R. China); ' Department of Medicine, Brigham and Women's Hospital and Harvard Medical School, Boston, MA (USA)

Cytogenet Genome Res 111:96E (2005) DOI: $\underline{10.1159 / 000085680}$

Assignment of the telomere-repeat binding factor genes TERF1 and TERF2 to Chinese muntjac $(2 n=46)$ chromosome bands $12 q 3$ and 2 q33 by in situ hybridization

N. Hartmann, ${ }^{a}$ H. Scherthan ${ }^{a, b}$

${ }^{a}$ Max Planck Institute for Molecular Genetics, Berlin; ${ }^{b}$ Institute for Radiation Biology Bundeswehr, Munich (Germany) 